\title{
Main Directions of Digitalization in China
}

\author{
Troshchinskiy P.V. \\ Center for Political Research and Prognosis \\ Institute of Far Eastern Studies of the Russian Academy of Sciences \\ Moscow, Russia \\ troshc@mail.ru
}

\begin{abstract}
The article is devoted to the study of the process of large-scale digitalization of the Chinese state, which has affected almost all spheres of the country's public life. Guided by exclusively pragmatic considerations, using vague legislation, the authorities of the People's Republic of China took the path of ousting foreign technology corporations from the Chinese market. The largest American (Western) platforms and business projects associated with them were blocked. In the absence of competition from their side, national Chinese platforms were created that took control of the republic's digital sphere. In parallel with the growth in the capitalization of Chinese digital platforms, systems of control over the population began to be created on their basis. First of all, a social rating system appeared. The law enforcement and judicial systems were gradually digitized. The rapid growth of China's digital economy, which is also dependent on the development of digital technologies, deserves special attention. Digital technologies played a positive role during the pandemic. Thanks to control systems, the use of artificial intelligence and "big data", it was possible to take control of the movement of the population, to predict the development of the pandemic, and to develop effective methods to combat the coronavirus. Despite the successes achieved in the development of digital technologies, there is still a danger of building a society of total control in modern China in the absence of a mechanism for their legal regulation necessary for such digital systems. It is obvious that the legislator is not keeping pace with the development of technologies. But this "lag" is explained more by political rather than objective reasons. The emergence of the necessary legislation will prevent manual control of the digital sphere, which is not in the political interests of the ruling class.
\end{abstract}

Keywords—digital technologies, digital economy, digital China, social rating system, Chinese law

\section{INTRODUCTION}

The outbreak of the global coronavirus pandemic has intensified the process of deep immersion of most countries in the world into the digital space. The question arose of the effectiveness of using digital technologies in predicting the development of the pandemic and fighting it $[1 ; 2]$. The Russian Federation, like many other countries, has also embarked on a large-scale introduction of digital technologies into the life of society. Particular attention is paid to the analysis of their impact on the employment of the population and socio-economic development [3]. To successfully solve the challenges facing the state in the digital sphere, domestic scientists turned to the experience of foreign countries, including the People's Republic of China. Unfortunately, Russian science, however, like our Western partners, to some extent does not keep pace with the development of digital technologies in China: there are still no comprehensive scientific studies of the political and legal aspects of their application in the PRC.

Note that, unlike the Russian Federation, by the beginning of the pandemic, China did not go online. China had been online for a long time already. In support of the above, we will give only some facts:

According to statistics (as of June 2020), the number of Internet users in China was about 904 million; the coefficient of spread of the Internet is $67 \%$; number of mobile Internet users - 932 million people; among all Internet users, mobile Internet users - 99.2\%; the number of users of online payment systems -749 million, or $79.7 \%$ of all Internet users (747 million via mobile phones or $80.1 \%$ of all mobile Internet users);

In 2019 , the total volume of the digital economy of the PRC reached 35.8 trillion yuan, which accounted for $36.2 \%$ of the country's GDP (in other words, over 1/3 of the entire Chinese economy was in the digital sphere) (for example, in $2005-14.2 \%$ ). The digital economy has penetrated almost all areas of the Chinese economy a long time ago [4]. At the same time, until recently, there was a "digital inequality", which means a different level of development of digital technologies in the eastern and western regions of China [5]. Currently, the situation is gradually leveling off.

The above statistics confirm China's leading position in the global digital economy. Although, as the Chinese scientists themselves testify, their country started its development late and for a long time lagged behind the USA and EU countries in this area [6]. If 10 years ago China accounted for a small share of the total value of world transactions in the framework of electronic digital transactions (about 1\%), now it is more than 40\% [7, p. 1384]. According to the Fletcher School index, the rate of digitalization of the Chinese economy is the highest in a sample of 62 countries [8]. 


\section{PLATFORMIZATION OF CHINA}

One of the main directions of China's digitalization was the creation of its own national platforms in the country that work completely independently and autonomously from external forces (without "relying" on foreign technologies), their capitalization did not depend on foreign investment. Platformization of China is made possible by a well-thoughtout and government-oriented legal policy in the area of legislation governing the digital economy and digital technologies. Through the adoption of a number of scattered local regulatory legal acts with an unspecified content, China was able to oust the world's leading giants from its markets.

Vague legislation allowed the Chinese authorities to protect the interests of their national companies from foreign competitors. The blocking of Google, Yahoo, YouTube, Facebook, Twitter, Flickr, Hotmail, Pinterest, WhatsApp, Instagram, Snapchat and others on the territory of the PRC led to the ousting from the Chinese market not only of the Western Internet sites themselves, but also of the largest business projects related to them. Instead, in the absence of competition, the world's largest "technological trinity" (abbreviated name: BAT) was created from the online platforms Baidu (analogous to Yahoo and Google ousted from the Chinese market), Alibaba (analogous to Amazon and eBay) and Tencent (created an analogue of the WhatsApp messenger which is blocked in China, WeChat), accumulating on their resources over 1 billion users around the world as well as information about them. It is no coincidence that, for example, the capitalization of the Chinese educational platform MOOC and its popularity in China [9] were the result of direct government support for its own "brands", the ousting of the American Coursera from the Chinese market.

The Internet space, mobile communications, payment systems, artificial intelligence and "big data" all work in China on Chinese platforms and are provided to users by national technology corporations. They also accumulate information that comes to them (e-mail, social networks, cash flow, online shopping, tracking movement (geolocation), dating applications, etc.) [10] and share it with the government. On the one hand, the use of their own platforms makes it difficult for foreign special services to access information about China, increasing the level of its state security. On the other hand, in the PRC there is no effective mechanism for protecting personal data; access to them for the ruling party and law enforcement officers is fairly free.

\section{CONTENT FILTERING}

Another important area of digitalization in China is the large-scale implementation of filtering systems for content passing through the Chinese segment of the Internet. Since 2003, the PRC has been implementing a large-scale project called The Golden Shield Project (unofficially known as the Great Firewall of China), which means a whole system for filtering the content of the Chinese Internet. Firewalls are used by providers to protect against viruses and hackers, but are also used to block access to certain sites and resources; for example, to the Google search engine [11]. The specialists responsible for the operation of the Golden Shield, using artificial intelligence, continuously monitor the activities of Internet users and suppress the spread of illegal information in the Chinese segment of the Internet. With the help of the
Golden Shield, prohibited IP addresses and Internet addresses (URLs) are blocked, DNS queries are filtered, VPN connections are blocked, etc.

Blocking of prohibited content and web pages is quite common in China. At the same time, some researchers believe that the cultural characteristics of certain users act as the main limiting factor in visiting prohibited sites than their prohibition by the state [12]. In other words, restricting access to certain resources and information does not lead to isolation of the Chinese from the outside world: they themselves, due to their mentality, would not turn to them.

\section{CONTROL SYSTEMS}

In the process of creating their own national platforms and filtering systems for Internet content, the Chinese authorities initiated the development and implementation of China-wide digital control systems. By 2020 in the PRC, the most developed were the "system of social trust (credit; rating)" and "face recognition system" based on the use of artificial intelligence and "big data".

The system of social trust began to form even under Mao Zedong, when special folders with personal information were added to certain categories of citizens. In the summer of 2014, the State Council of the People's Republic of China promulgated the "Program-Plan for the Creation of a Social Credit System (2014-2020)", which assumed the final construction of the system and the implementation of accounting over all Chinese citizens through 2020. The pilot launch of the system involved the assignment of a certain number of points to each citizen and their distribution into groups depending on the assigned rating.

An account created in the system of social trust (credit) becomes a "second passport" or "reputation index" (ranking system) of a citizen: not only credit history is entered into it, but also the history of taxes, utility bills, convictions, rewards and punishments, attitude to the ruling party and generally accepted moral norms, as well as information about close relatives to form a "general assessment" of the individual. In other words, the rating is based on data on the behavior of citizens and companies, their attitude to the ruling regime and socialist morality.

Individuals and legal entities, as well as other organizations that have lost confidence, are included in a special "black list" (for the first time such a system was introduced by the Supreme People's Court in 2013), which is public; the employer or contractor, prior to the conclusion of an employment or commercial contract, checks the person against this list. If a person is included in the list, then no cooperation relationship is established with them. With regard to legal entities and other organizations, the system began to be implemented in the fall of 2019 .

To date, a Unified "Trust" platform has been created at https://www.creditchina.gov.cn/, which over time will turn into the National Base of Credit Evaluation of Individuals and Organizations. The assignment of a trust rating began to be tested in relation to foreign citizens and commercial enterprises. From time to time there are some analytical publications of independent experts on the operation of the system in various regions of China [13], however, there is still very little reliable, complete official information about it. The 
Chinese authorities are in no hurry to remove the "classification" from it.

The Chinese system of social trust is almost unanimously assessed by foreign and Russian experts as a system of digital authoritarianism. But there are still other opinions. So, for example, A.D. Trakhtenberg believes that "the comprehensive system of social credit is still rather a propaganda project that instills optimism in the citizens of the PRC and generates dystopian fears in the outside world" [14].

\section{V.DIGITALIZATION OF THE JUDICIAL AND LAW ENFORCEMENT SYSTEMS}

The PRC judicial system has undergone large-scale digitalization, for which new technological capabilities have been created for electronic document management, remote administration of justice. Chinese courts have begun to partially use artificial intelligence in lawsuits. Testing of "smart courts" has been launched, in which the proceedings are conducted using digital technologies, sometimes even without the participation of a judge. In February 2019, the creation of "smart courts" was included in the "Plan for the reform of the people's courts for the fifth five years (20192023)", which outlines the use of Big Data technologies (court decisions, claims, contracts, consultations, etc.), speech recognition, etc. during the operation of "smart courts".

Artificial intelligence is also used by Chinese law enforcement to combat crime (predicting the likelihood of committing crimes). The created IJOP (Integrated Joint Operations Platform) system works with "big data" (collected using video cameras installed on streets, gas stations, schools, etc.) and "identifies" suspicious persons for the system through analyzing their personal information, movement, contacts, purchases, etc. The system is used in the Xinjiang Uygur Autonomous Region (in a region with a high level of terrorist threat). All this raises concerns in the aspect of establishing digital control over citizens in the absence of a transparent mechanism for its legal regulation and protection of personal data of a citizen from illegal access to them by the administrative apparatus.

\section{NEW TECHNOLOGIES IN THE SERVICE OF FIGHTING THE PANDEMIC}

Facial recognition and artificial intelligence technologies have played a particularly positive role in the fight against coronavirus. Artificial intelligence as a tool for population control in a pandemic has proven to be highly effective. The absence of a mandatory medical mask, violation of the quarantine regime was recorded by cameras on the streets, at the entrance to institutions, airports, train stations, shopping centers, etc. The information received was instantly processed by artificial intelligence and transmitted to the law enforcement officer for taking the necessary measures.

Artificial intelligence technologies were actively used in the field of predicting the spread of coronavirus [15] and its treatment: by analyzing big data, a huge array of information about the virus was analyzed and the measures necessary to combat it were developed. During the battle against the pandemic, the Alibaba DAMO Institute prepared an artificial intelligence system to recognize the coronavirus in a patient with an accuracy of $96 \%$ within 20 seconds.
In the midst of the pandemic, "remote automatic temperature measurement systems" (thermal imaging cameras) were widely used in public places. Chinese police, medical personnel and transport workers use smart helmets that automatically detect the temperature of passers-by at a distance of about 2; "Movement tracking system" (via cellular applications) using the so-called "health code" - a mini-program with a color code assigned to a person: green free movement; yellow - self-isolation for 7 (14) days at the place of residence/stay; red - quarantine for 14 days in a specially designated place); "Unmanned aerial vehicles" (drones) with attached cameras with face recognition function for patrolling the streets, automatically detecting body temperature, spraying disinfectants, identifying persons who violated the quarantine regime; "Courier robots" (delivery of goods ordered through online platforms) and "disinfection robots" (disinfection of crowded places, quarantine zones).

Digital technologies were actively used in social, educational, medical spheres. So, for example, the PRC health authorities have scaled online consultations to the population as part of the mental health care of citizens in isolation, in quarantine due to the spread of the virus [16].

During the pandemic, the court sessions were not postponed: they were moved online. A special platform has begun to be tested: "litigation in the cloud" (in Beijing, from 03.02.2020, a "cloud court" began to work).

Pilot testing of the so-called "digital yuan" (digital currency of electronic payments) in mid-April became important for the process of total digitalization in China in 2020. The digital yuan is planned to be used both for payments within the PRC and outside the republic. The Chinese national currency will be fully controlled by the government and integrated into the PRC banking system.

\section{CONCLUSION}

In the process of building a digital society, China has taken all the necessary measures to protect its own "digital sovereignty" by securing control over the Chinese segment of the Internet. Sovereign digital infrastructure, sovereign Internet, increasing technological independence, "import substitution", strict regulation of the digital sphere and the Internet space, storing big data only in the country, banning foreign Internet corporations in China, creating a "united digital front" - that's just some of the important features of Chinese digitalization that distinguish it from Russian. The Russian Federation, standing on the position of Eurocentrism, "capitulated" to Western technologies, having undergone "digital occupation" on their part, losing almost completely information and digital sovereignty. The "Western landing" in the form of various programs, platforms, technical devices, "landed" on Russian soil, actively supports the invasion of Western interests into our jurisdiction. The Chinese partners have proposed a different digitalization model based on their own technologies and filtering the passing content. Thanks to this, their national interests and state security were under more comprehensive protection.

At the same time, the rapid development of new technologies in China leads to a large-scale "digitization" of a person and, as a result, to the loss of their privacy in the face of total digital control by the ruling Communist Party and 
state bodies. The process of digitalization of the Chinese society is taking place against the background of the absence of any full-fledged legal regulation of the ongoing changes that violate the personal boundaries of the individual. The party invades the personal space of a citizen, which is not protected by law. The PRC has not adopted the Law on the Protection of Personal Information; the mechanism for protecting the personal rights of a citizen, enshrined in the Constitution and laws, does not work. There is a significant backlog of formal mandatory regulation from the development of digital technologies.

Despite the well-known deliberate lag in the legal regulation of the digital sphere, we note the positive role of digital technologies that they played in the battle against coronavirus infection. Due to the fact that by the beginning of the pandemic they were already widely introduced into the life of society, their use during the pandemic helped to protect the population from the virus. Artificial intelligence technologies have played a special role in this process. With the help of AI, it was possible in the shortest possible time to limit the movement of the population, predict outbreaks of the pandemic, conduct large-scale studies of the virus in order to develop a vaccine and treatment methods, create the necessary drugs. In the area of artificial intelligence regulation, China faces a number of challenges that will take a long time to overcome. However, similar problems are inherent in many other foreign countries [17].

We need to look for a "golden mean" between the Chinese experience of completely closing the "Internet borders" and the unregulated freedom of the Internet inherent in modern Russia. It is unlikely that the Chinese experience can be completely transferred to our soil, but it is also unacceptable to leave the "borders" in such a state as now.

\section{Acknowledgment}

The project was financially supported by the Russian Foundation for Basic Research, project No. 18-29-16223 "Legal regulation of relations associated with the use of digital technologies in Russia and China: a comparative legal analysis".

\section{References}

[1] S. Whitelaw, M.A. Mamas, E. Topol and H.G.C. Van Spall, "Applications Of Digital Technology In COVID-19 Pandemic Planning And Response", The Lancet Digital Health, 2020, vol. 2, pp. e435-e440. DOI: https://doi.org/10.1016/S2589-7500(20)30142-4
[2] D.S.W. Ting, L. Carin, V. Dzau and T.Y. Wong, "Digital Technology And COVID-19”, Nature Medicine, 2020, vol. 26(4), pp. 459-461. DOI: https://doi.org/10.1038/s41591-020-0824-5

[3] J.V. Ivanchina and Ye.A. Istomina, "The Impact of Digital Technology on the Labor and the Socioeconomic Development in Modern Russia", Proceeding of the International Science and Technology Conference "FarEastCon 2019", 2020, pp. 813-824. DOI https://doi.org/10.1007/978-981-15-2244-4_77

[4] S. Grimes, "Networking China: The Digital Transformation Of The Chinese Economy", Chinese Journal of Communication, 2018, vol. 11, vol. $2, \quad$ pp. $236-241 . \quad$ DOI: https://doi.org/10.1080/17544750.2018.1466484

[5] H. Liu, C. Fang and S. Sun, "Digital Inequality In Provincial China", Environment and planning a-economy and space, 2017, vol. 49(10), pp. 2179-2182. DOI: https://doi.org/10.1177/0308518X17711946

[6] Digital transformation of China. Experience in transforming the infrastructure of the national economy. Ed. Ma Huateng. Moscow: Alpina Publisher, 2019. 250 p.

[7] S. Van Syuna and E.V. Murashova, "The Current State Of The Digital Economy In China”, Scientific notes of PNU, 2018, vol. 9(3), pp.13831386

[8] L. Dzhan, S. Chen, "China's digital economy: opportunities and risks", Bulletin of international organizations, 2019, vol. 14(2), pp. 275-303. DOI: 10.17323/1996-7845-2019-02-11

[9] Q.H. Zheng, L. Chen and D. Burgos, "Construction Of MOOC Platforms In China", Development of voocs in China, 2018, pp.43-83. DOI: https://doi.org/10.1007/978-981-10-6586-6_5

[10] T. Fu, "China's Personal Information Protection In A Data-Driven Economy: A Privacy Policy Study Of Alibaba, Baidu And Tencent", Global Media and Communication, 2019, vol. 15(2), pp. 195-213. DOI; https://doi.org/10.1177/1742766519846644

[11] S.W. Kim and A. Douai, "Google vs. China's "Great Firewall": Ethical Implications For Free Speech And Sovereignty", Technology in Society, 2012, vol. 34(2), pp. 174-181. DOI: https://doi.org/10.1016/j.techsoc.2012.02.002

[12] H. Taneja and A.X. Wu, "Does the Great Firewall Really Isolate the Chinese? Integrating Access Blockage With Cultural Factors to Explain Web User Behavior”, Information Society, 2014, vol. 30(5), pp. 297-309. DOI: https://doi.org/10.1080/01972243.2014.944728

[13] N. Raghunath, “A Sociological Review of China's Social Credit Systems and Guanxi Opportunities for Social Mobility", Sociology Compass, 2020, vol. 14(5), e12783 p. DOI: https://doi.org/10.1111/soc4.12783

[14] A.D. Trahtenberg, "The Chinese System Of Social Credit: A View From The Outside And From The Inside", Scientific journal "Discourse-Pi", 2019, vol. 4(37), pp. 108-118. DOI: 10.24411/18179568-2019-10407

[15] H. Zixin, G. Qiyang, L. Shudi, J. Li and X. Momiao, "Artificial Intelligence Forecasting of Covid-19 in China", 2020. Retrieved from: https://arxiv.org/abs/2002.07112

[16] S. Liu, L.L. Yang, C.X. Zhang, Y.T. Xiang, Z.C. Liu, S.H. Hu and B Zhang, "Online Mental Health Services In China During The COVID19 Outbreak", Lancet Psychiatry, 2020, vol. 7(4), pp. E17-E18. DOI https://doi.org/10.1016/S2215-0366(20)30077-8

[17] "Legal regulation of artificial intelligence in the context of a pandemic and infodemic", Under the general editorship of prof. V.V. Blazheev and prof. M.A. Egorova. M .: Moscow State Law Institute named after O.E. Kutafina, 2020, 240 p. 